\title{
Facile synthesis of porous cobalt oxides through solvothermal method
}

\author{
Lijuan Wan $^{1,2^{*}}$ \\ ${ }^{1}$ Nanjing Communications Institute of Technology, Nanjing 211188, China; \\ 2 Jiangsu Engineering Technology Research Center for Energy Conservation and Emission \\ Reduction of Transportation, Nanjing 211188, China. \\ *bartty_ym@163.com.
}

Keywords: cobalt oxide; solvothermal; porous

\begin{abstract}
The morphology may significantly influence the properties and applications of materials, thus the ability to tune the structure, size, and shape of inorganic materials is an important goal in obtaining nanomaterials with novel properties. A novel and facile synthesis route for the manufacture of porous $\mathrm{Co}_{3} \mathrm{O}_{4}$ is reported, utilizing cobalt nitrate as the inorganic source and triblock copolymer F127 as the morphology-directing agent by the solvothermal method. X-ray powder diffraction (XRD), $\mathrm{N}_{2}$-sorption and scanning electron microscopy (SEM) were used to characterize the as-prepared $\mathrm{Co}_{3} \mathrm{O}_{4}$. The possible formation mechanism of the porous $\mathrm{Co}_{3} \mathrm{O}_{4}$ was discussed.
\end{abstract}

\section{Introduction}

Release of various organic pollutants including the volatile organic compounds (VOCs) such as textile dyes, phenols and aromatic amines from many industries is becoming a serious problem. There are many techniques to remove the organic pollutants. The techniques include adsorption, catalytic combustion, photocatalytic degradation and physical separation. Co3O4 with the normal spinel structure, where $\mathrm{O} 2-$ is cubic close packed, $\mathrm{Co} 2+$ in atetrahedral coordination and $\mathrm{Co} 3+$ in an octahedral coordination, is a magnetic semiconductor. The lowest Co-O bonds strength and the highest capability of the activation of molecule oxygen play crucial roles in the catalytic oxidation systems [1]. Due to its special physical and chemical properties, Co3O4 is widely used in magnetism [2], photovoltaics [3,4], sensors [5] and homogeneous catalysis [6]. Furthermore, among metal oxides, the Co3O4 based materials are of great interest as a photo-Fenton catalyst due to their low cost, natural abundance, visible light absorption and most importantly the good catalytic activity toward degradation of organic compounds even at neutral $\mathrm{pH}$ [7]. Co3O4 material is also regarded as promising anode for high performance Li-ion batteries (LIBs) due to its high energy density, high tap density and stable chemical property [8].

The structure (microstructure), size, and morphology may significantly influence the material properties and application, thus controlling the morphology of inorganic nanomaterials plays a important role in obtaining nanomaterials for novel properties. For the improved catalytic activity and increasing applications in various fields, the development of catalysts with desirable morphology and dimensions is a challenging task [9]. The morphology of Co3O4 based nanomaterials is diverse and experimentally available owing to the special spinel structure. Furthermore, Co3O4 is one of the most intriguing p-type semiconductors with various morphologies, which has been used in a wide range of applications such as photocatalysis [10].

The properties of the as-synthesized Co3O4 strongly depend on their morphologies and structure, for example, the superior electrochemical performance is attributed to the porous structures of Co3O4. Hence, the synethsis of porous $\mathrm{Co} 3 \mathrm{O} 4$ is of great importance. Porous Co3O4 has been synthesized by some methods including electrochemical method [11], Pulsed Laser Deposition (PLD) and thermal oxidation [12] and microwave-assisted method [13]. In this study, we report the facile synthesis of porous cobalt oxide (Co3O4) through solvothermal route in an environmentally benign alcohol-water mixture. The growth mechanism of porous cobalt oxide was also investigated. 


\section{Experimental Section}

\subsection{Materials}

Triblock copolymer Pluronic F-127 (EO106PO70EO106, MW=12600, product no. P2443-250G) was purchased from Aldrich and used as received without further purification.

\subsection{Synthesis of $\mathrm{Co3O} 4$}

In a typical experiment, isotropic solutions were prepared by dissolving $\mathrm{Co}(\mathrm{NO} 3) 2 \cdot 6 \mathrm{H} 2 \mathrm{O}$ or $\mathrm{CoCl} \cdot 6 \mathrm{H} 2 \mathrm{O}$ (0.1 mol) and block copolymer F-127 (EO106PO70EO106) (0.9 g) in EtOH (23 mL), $\mathrm{H} 2 \mathrm{O}(20 \mathrm{~mL})$ and $26-28 \% \mathrm{NH} \cdot \mathrm{H} 2 \mathrm{O}(4.5 \mathrm{~mL})$. The solution was stirred at $70{ }^{\circ} \mathrm{C}$ for $1 \mathrm{~h}$, then it was transferred into a Teflon-lined stainless steel autoclave and heated at $150{ }^{\circ} \mathrm{C}$ for $16 \mathrm{~h}$. To remove the surfactant, the as-prepared products were washed with water, and then the sample was dried and calcined at $450{ }^{\circ} \mathrm{C}$ for $4 \mathrm{~h}\left(1{ }^{\circ} \mathrm{C}\right.$ min-1 under air).

\subsection{Characterization}

The crystalline phase and orientation of products were identified by X-ray diffraction (XRD) on a Rigaku D/MAX-Ultima III X-ray diffractometer with $\mathrm{Cu} \mathrm{K \alpha}$ radiation $(\lambda=0.154 \mathrm{~nm}, 40 \mathrm{kV}, 40 \mathrm{~mA})$ and a scan rate of $10^{\circ} \cdot \min -1$. The microstructure of the as-prepared products was characterized by a field emission scanning electron microscopy (FE-SEM, S4800, Hitachi Ltd.) with an electron accelerating voltage of $15 \mathrm{kV}$. The specific surface area of the as-prepared $\mathrm{NiO}$ powders was obtained on a Micromeritics TriStar 3000 instrument and the Brunauer-Emmett-Teller (BET) equation was used to calculate the specific surface area.

\section{Results and Discussion}

Fig. 1 shows the structural characteristics of the sample prepared through the solvothermal route by using $\mathrm{Co}(\mathrm{NO} 3) 2 \cdot 6 \mathrm{H} 2 \mathrm{O}$ in the starting solution investigated by XRD. The diffraction peaks typical to Co3O4 are clearly observed, which agree with those of standard Co3O4 of cubic structure (JCPDS Card No. 43-1003). There are no other peaks observed in the XRD result except for the diffraction peaks of Co3O4, which means single-phase $\mathrm{Co3O} 4$ can be obtained route in this system through solvothermal route.

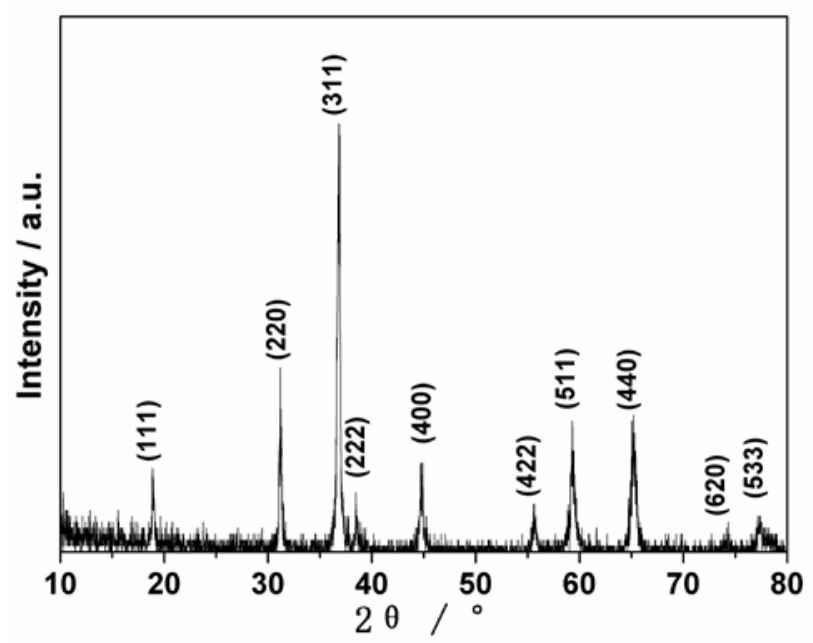

Fig. $1 \mathrm{XRD}$ pattern of the product calcined at $450{ }^{\circ} \mathrm{C}$ synthesized by using $\mathrm{Co}\left(\mathrm{NO}_{3}\right)_{2} \cdot 6 \mathrm{H}_{2} \mathrm{O}$ as precursor.

The morphology of the as-prepared Co3O4 sample was characterized by FE-SEM and the images are shown in Fig. 2. From Fig. 2, the low-magnification SEM image (see Fig. 2a) of the as-prepared Co3O4 by using $\mathrm{Co}(\mathrm{NO} 3) 2 \cdot 6 \mathrm{H} 2 \mathrm{O}$ as precursor shows a uniform plate morphology. The high-magnification SEM image (see Fig. 2b) shows of the as-prepared Co3O4 sample has prous structure. The BET surface area of the as-prepared Co3O4 sample $15.09 \mathrm{~m} 2 \mathrm{~g}-1$. 


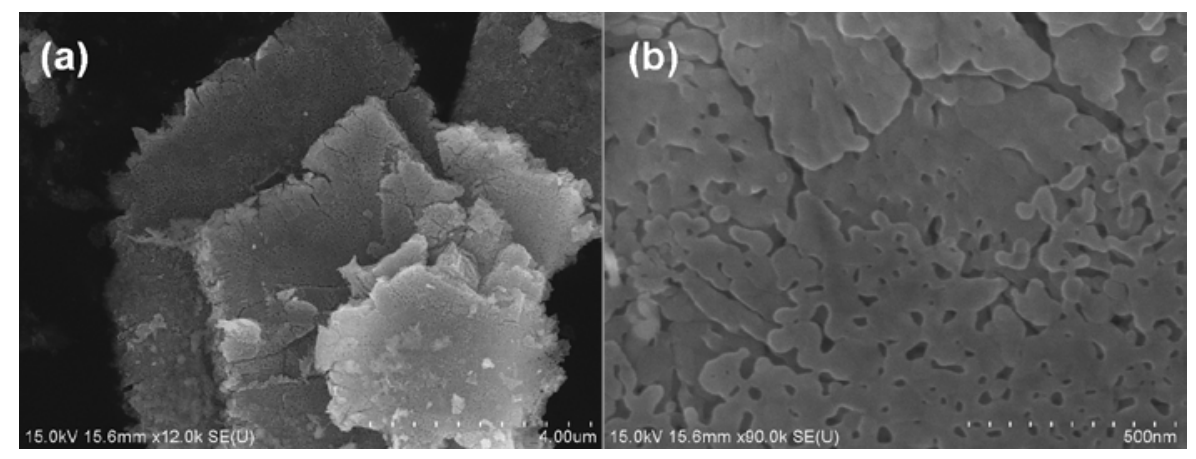

Fig. 2 SEM images of the product calcined at $450{ }^{\circ} \mathrm{C}$ synthesized by using $\mathrm{Co}\left(\mathrm{NO}_{3}\right)_{2} \cdot 6 \mathrm{H}_{2} \mathrm{O}$ as precursor.

Fig. 3 shows the low- and high magnification SEM images of the as-prepared Co3O4 by using $\mathrm{CoCl} 2 \cdot 6 \mathrm{H} 2 \mathrm{O}$ in the starting solution. From Fig. 3a, the low-magnification SEM image shows the Co3O4 particles morphology. From Fig. 3b, the high-magnification SEM image shows the morphology of the Co3O4 particles is polyhedron-like shape.

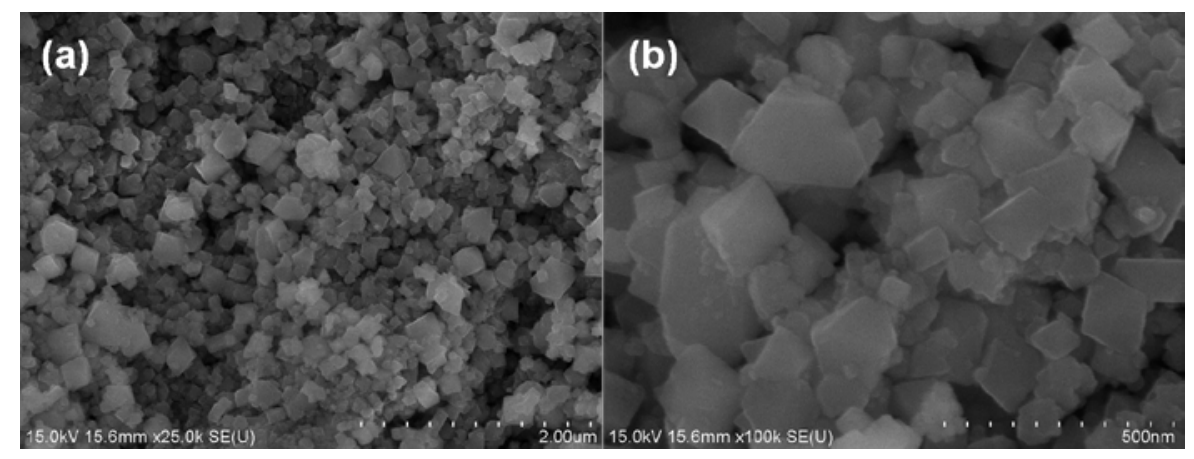

Fig. 3 SEM images of the product calcined at $450{ }^{\circ} \mathrm{C}$ synthesized by using $\mathrm{CoCl}_{2} \cdot 6 \mathrm{H}_{2} \mathrm{O}$ as precursor.

In a triblock copolymer-solvent system, it is well known that block copolymers can self-assemble to a variety of lyotropic liquid crystals microstructures consisting of lamellar, hexagonal or cubic structure [14]. The very rich structural polymorphism of block copolymer in a ternary system makes it possible to synthesize various nanostructured materials. The factors which influence the synthesis of $\mathrm{Co3O} 4$ nanoparticles are supposed to exist in the following two ways: the strong gelation tendency inside the precursors when they hydrolyze; the potential disruption of the assembly of nanoparticles in process of conformation of crystal phase and the removal of template. Thus, the formation of porous $\mathrm{Co3O} 4$ can be attributed to the interaction between morphology-directing agent and hydrophilic cobalt nanoclusters and the following removal of surfactant.

\section{Conclusions}

In summary, porous cobalt oxide (Co3O4) is synthesized through solvothermal route using cobalt nitrate as the inorganic source and F127 as structure-directing agent in an environmentally benign alcohol-water mixture. The growth mechanism of porous cobalt oxide has been investigated. The formation of porous $\mathrm{Co3O} 4$ can be attributed to the interaction between morphology-directing agent and hydrophilic cobalt nanoclusters. Co3O4 with the porous structure may be used in many ways such as the superior electrochemical performance.

\section{Acknowledgement}

This work was supported by a grant from Scientific Research Project of Nanjing Communications Institute of Technology (JY1304), High-level Scientific Research Foundation for the introduction of talent of Nanjing Communications Institute of Technology and Qing Lan Project of Nanjing 
Communications Institute of Technology.

\section{References}

[1] X.F. Tang, J.H. Li, J.M. Hao, Synthesis and characterization of spinel $\mathrm{Co}_{3} \mathrm{O}_{4}$ octahedra enclosed by the $\left\{\begin{array}{lll}1 & 1 & 1\end{array}\right\}$ facets, Mater. Res. Bull. 43 (2008) 2912-2918.

[2] M.S. Wang, L.K. Zeng, Q.W. Chen, Controlled synthesis of $\mathrm{Co}_{3} \mathrm{O}_{4}$ nanocubes under external magnetic field and their magnetic properties, Dalton Trans. 40 (2011) 597-601.

[3] X.D. Lou, J. Han, W.F. Chu, X.F. Wang, Q.T. Cheng, Synthesis and photocatalytic property of $\mathrm{Co}_{3} \mathrm{O}_{4}$ nanorods, Mater. Sci. Eng. B 137 (2007) 268-271.

[4] F.F. Tao, C.L. Gao, Z.H. Wen, Q. Wang, J.H. Li, Z. Xu, Cobalt oxide hollow microspheres with micro- and nano-scale composite structure: fabrication and electrochemical performance, J. Solid State Chem. 182 (2009) 1055-1060.

[5] H.W. Che, A.F. Liu, J.X. Hou, X.L. Zhang, Y.M. Bai, J.B. Mua, R.L. Wang, Synthesis of one-dimensional porous $\mathrm{Co}_{3} \mathrm{O}_{4}$ nanobelts and their ethanol gas sensing properties, Materials Research Bulletin 59 (2014) 69-76.

[6] X.W. Xie, Y. Li, Z.Q. Liu, M. Haruta, W.J. Shen, Low-temperature oxidation of CO catalysed by $\mathrm{Co}_{3} \mathrm{O}_{4}$ nanorods, Nature 458 (2009) 746-749.

[7] R. Edla, N. Patel, Z. ElKoura, R. Fernandes, N. Bazzanella, A. Miotello, Pulsed laser deposition of $\mathrm{Co}_{3} \mathrm{O}_{4}$ nanocatalysts for dye degradation and $\mathrm{CO}$ oxidation, Appl. Surf. Sci. 302 (2014) $105-108$.

[8] G.Y. Huang, S.M. Xu, S.S. Lu, L.Y. Li, H.Y. Sun, Porous polyhedral and fusiform $\mathrm{Co}_{3} \mathrm{O}_{4}$ anode materials for high-performance lithium-ion batteries, Electrochimica Acta 135 (2014) 420-427.

[9] P. Sun, Z. Zhu, P. Zhao, X. Liang, Y. Sun, F. Liu, G. Lu, Gas sensing with hollow $\alpha-\mathrm{Fe}_{2} \mathrm{O}_{3}$ urchin-like spheres prepared via template-free hydrothermal synthesis, CrystEngComm 14 (2012) 8335-8337.

[10] J.R. Huang, H.B. Ren, K.K. Chen, J.J. Shim, Controlled synthesis of porous $\mathrm{Co}_{3} \mathrm{O}_{4}$ micro/nanostructures and their photocatalysis property, Superlattices and Microstructures 75 (2014) 843-856.

[11] Z.G. Liu, X. Chen, J.H. Liu, X.J. Huang, Well-arranged porous $\mathrm{Co}_{3} \mathrm{O}_{4}$ microsheets for electrochemistry of $\mathrm{Pb}(\mathrm{II})$ revealed by stripping voltammetry, Electrochemistry Communications 30 (2013) 59-62.

[12] R. Edla, N.Patel, M.Orlandi, N.Bazzanella, V.Bello, C.Maurizio, G.Mattei, P. Mazzoldi, A.Miotello, Highly photo-catalytically active hierarchical 3D porous/urchin nanostructured $\mathrm{Co}_{3} \mathrm{O}_{4}$ coating synthesized by Pulsed Laser Deposition, Applied Catalysis B: Environmental 166-167 (2015) 475-484.

[13] F. Sun, K. Huang, X. Qi, T. Gao, Y.P. Liu, X.H. Zou, J.X. Zhong, Enhanced 3D hierarchical double porous $\mathrm{Co}_{3} \mathrm{O}_{4}$ /graphene architecture for superior rechargeable lithiumion battery, Ceramics International 40 (2014) 2523-2528.

[14] P. Alexandridis, U. Olsson, B. Lindman, Modification of the Microstructure in Block Copolymer-Water-“Oil” Systems by Varying the Copolymer Composition and the "Oil” Type: Small-Angle X-ray Scattering and Deuterium-NMR Investigation [J]. J. Phys. Chem. B 102 (1998) 1149-1158. 